\title{
Releitura estética e histórica em Longe do Paraíso, de Todd Hayness
}

\author{
Lajosy Silva ${ }^{1}$
}

\begin{abstract}
RESUMO
Este artigo pretende analisar o filme Longe do Paraíso como representação histórica do Pós-Guerra nos Estados Unidos e crítica à ideologia dominante do Sonho Americano, assim como aspectos da estética do melodrama, seus conceitos e impacto na discussão da discriminação racial, da homossexualidade e da condição feminina.

Palavras-chave: Cinema; História; Melodrama.
\end{abstract}

\begin{abstract}
This article aims to analyze the movie Far from Heaven as historical representation of the Post-War years in the US and criticism to the American Dream. This article also develops a reflection on aesthetic aspects of melodrama, its concepts and impact when dealing with themes such as racism, homosexuality and female condition.
\end{abstract}

Key-words: Cinema; History; Melodrama.

Longe do Paraíso (2002) tornou-se um projeto do diretor Todd Haynes que pretendia homenagear os filmes do diretor alemão Douglas Sirk, famoso diretor de melodramas nos anos cinquienta e sessenta em Hollywood. Trata-se de um filme no qual se relê a história americana a partir da retomada de um gênero, o melodrama, estabelecendo uma ligação entre o passado (os Estados Unidos do pós-guerra) e o presente (o conservadorismo da Era Bush).

Amparado na estética do melodrama, cuja tradição se inicia no drama burguês do século XVIII, Douglas Sirk criou inúmeros filmes que hoje são paradigmas de melodromas que descrevem uma visão da sociedade norte-americana embriagada pelo retomada econômica do pós-guerra, suas contradições e sonhos. All that Heaven

${ }^{1}$ Lajosy Silva é Mestre em Estudos Literários pela UNESP - Araraquara. Doutorando em Estudos Lingüísticos e Literários em Inglês na USP - Universidade de São Paulo. 
Allows (1955), Written on the Wind (1956), Immitation of Life $(1959)^{2}$ fazem parte de uma lista de filmes que o cineasta alemão dirigiu em Hollywood, quando alguns artistas estrangeiros deixaram a Europa, devido à ascensão do nazismo: Billy Wilder ${ }^{3}$, Otto Preminger ${ }^{4}$, dentre tantos outros.

$\mathrm{Na}$ época, a crítica não reconhecia a leitura que Douglas Sirk fazia da sociedade norte-americana, uma vez que, ao utilizar o melodrama, ele teria disfarçado muitas das questões que o filme tinha como germes de pensamento crítico (ou estrutura de sentimento, conforme termo de Raymund Williams) ao descrever uma sociedade perturbada e incapaz de lidar com uma economia crescente e a concretização do American Dream no imaginário popular americano.

$\mathrm{O}$ conceito de Sonho Americano tende a gerar debates infrutíferos a respeito da pertinência do termo por parte de pesquisadores e críticos que acham que utilizá-lo implica endossá-lo numa certa medida, ou reafirmá-lo como uma ideologia que procura legitimá-lo. O foco do artigo não é discutir se o termo é pertinente, mas sim apontá-lo como algo maior dentro de uma ideologia dominante ou como Ideologia do Estado sob a égide do patriarcado protestante.

Não há como negar que os filmes de Douglas Sirk eram produções elegantes e requintadas dentro dos padrões hollywoodianos, vendidos como produto de consumo de um segmento da indústria cultural para um público fascinado com a qualidade das imagens projetadas pelo diretor, figurinos e descrição de uma sociedade de classe média alta.

É importante ressaltar que todos esses elementos do melodrama advêm do drama burguês do século XVIII, isto é, têm suas origens no teatro, peças que

\footnotetext{
${ }^{2}$ Tudo o que o Céu permite, Palavras ao Vento e Imitação de Vida. Todos esses títulos foram lançados comercialmente no Brasil, mas apenas o penúltimo está disponível em DVD atualmente (2005).

${ }^{3}$ Billy Wilder (1906-2002), diretor polonês, conhecido por dirigir comédias ousadas como Quanto mais Quente Melhor, e críticas contundentes ao establishment hollywoodiano, como em Crepúsculo dos Deuses.

${ }^{4}$ Otto Preminger (1906-1986), diretor austríaco, conhecido como diretor e produtor ousado para os padrões hollywoodianos, o primeiro a escalar uma protagonista negra, em Carmen Jones, a ópera de Bizet para a classe operária num elenco composto por negros. Ele também foi um dos primeiros diretores a inserir o tema da dependência química no filme $O$ Homem do Braço de Ouro (1955).
} 
descrevem o cotidiano da burguesia européia. Dramas como A Dama das Camélias de Alexandre Dumas Filho publicado em 1857, dentre tantos outros, eram bastante populares entre as camadas sociais mais baixas, que poderiam adquirir um ingresso para assistir aos espetáculos de companhias fixas ou itinerantes na Europa; tradição esta bastante comum no cenário norte-americano, como bem retrata a peça Longa Jornada Noite Adentro de Eugene O'Neil, ao descrever o patriarca da família, um ator de teatro famoso por interpretar um único papel ao longo de uma carreira de décadas, o Conde de Monde Cristo, uma versão teatral adaptada do romance de Alexandre Dumas.

O melodrama é um subproduto da burguesia do século XVIII, mas nasceu das camadas sociais mais baixas, e não da burguesia. Surgiu entre aqueles que só passaram a ter acesso ao teatro após a Revolução Francesa, especialmente após uma determinação legislativa de 1791, que autorizava qualquer cidadão a construir um teatro e a encenar peças de todos os gêneros que desejasse, ou seja, não surgiu dentre aqueles que podiam pagar o ingresso, mas das camadas populares, cujos desejos e valores ele representava. $\mathrm{O}$ que aconteceu é que o melodrama acabou caindo no gosto tanto da burguesia como da própria aristocracia, já que ele não pressupunha nenhuma forma de insurgência ou crítica contra os poderes dominantes.

Além do teatro, o melodrama de Douglas Sirk tem como inspiração os filmes mudos dos anos 30, quando diretores como D. W. Griffith inauguraram o gênero no cinema, transpondo temas como o alcoolismo, a desintegração familiar e a independência feminina. Immitation of Life, por exemplo, é uma adaptação da obra Sing House de Fannie Hurst, escritora bastante popular na época, e que teve várias obras adaptadas para o cinema mudo. A primeira adaptação da obra de Hurst foi realizada por John M. Stahl em 1934, uma outra versão dirigida por Douglas Sirk em 1959.

Os filmes de Sirk alcançavam sucesso perante o público, enquanto eram desprezados pela crítica, que descrevia defeitos estruturais nas suas narrativas ou seu caráter meramente comercial. Com o surgimento da TV, os elementos formais e estéticos dos melodramas de Sirk foram transferidos para a teledramaturgia, as soap 
operas americanas (para nós, as telenovelas), patrocinadas por marcas de sabão e exibidas durante o dia, entretendo as donas de casa americanas, sem profissão, divididas entre as tarefas domésticas e a educação dos filhos. Esse sistema de produção foi copiado por muitos países: México e Brasil são os que mais se beneficiaram, sendo herdeiros dessa tradição, produtos de entretenimento com alto nível de produção para o horário nobre, o prime time americano. As soap operas americanas tornaram-se subprodutos com baixo custo e ocupam um espaço cada vez mais reduzido na TV, dado que seu público-alvo, as mulheres e antigas donas de casa, tornaram-se independentes economicamente, deixando a ociosidade do Home Sweet Home para trabalhar fora e adquirir uma profissão, contribuindo para o avanço dos movimentos feministas no final da década de sessenta.

É interessante rever o quanto a tradição da teledramaturgia no Brasil ainda permanece parcialmente intacta a essas transformações, apesar de todas essas revoluções comportamentais: o feminismo e a liberação sexual; bem como o desgaste da fórmula da telenovela. Contudo, a crise na estrutura formal da teledramaturgia brasileira aponta para outras possibilidades que procuram reformular um gênero gasto, quando teledramaturgos brasileiros inserem temas como o movimento sem terra, a doação de órgãos, a imigração clandestina de brasileiros aos Estados Unidos; que não teriam qualquer relação com a estrutura formal e o conteúdo do drama burguês, reduzido à sala de visitas e a descrição de pequenos incidentes domésticos.

Contudo, isso não quer dizer que haja um aspecto crítico e inovador nas telenovelas, porém, uma sistematização de temas que são usados oportunamente para dar ao melodrama a característica de novidade. A constante renovação do conteúdo parece sugerir que a estrutura formal do melodrama pode se adaptar a qualquer tema proposto, desde que ele estabeleça uma relação entre sua fórmula tradicional (emoção, sentimentalismo e catarse) e flexibilidade da narrativa para condensar idéias inovadoras e tirar qualquer possibilidade de aprofundamento. De fato, a tv parece construir um amálgama de elementos conflitantes, de questões sociais e comportamentais que estão eclodindo na sociedade, tragando-os para o seu sistema dominante e contribuindo para sua diluição. 
É compreensível que os melodramas de Douglas Sirk tenham seu contexto histórico reduzido, representado por dramas que, na época, foram vistos como "novelões elegantes", mas que hoje permitem uma compreensão do vazio herdado pelo fortalecimento de uma classe média arrivista e competitiva como a americana. A emoção pode solapar a visão do espectador mediano, acostumado a ser adestrado pela estrutura formal da narrativa, entendida aqui como a valorização do sentimentalismo em oposição ao distanciamento crítico. Sustentar-se em arquétipos primários (ou estereótipos) parece ser o que define o melodrama enquanto estética da emoção vulgar; porém descartar seus aspectos ideológicos e políticos pode ser mais perigoso do que evitá-lo, com o intuito de buscar elementos épicos na valorização da política explícita como representação artística.

Em Longe do Paraíso, a estrutura do melodrama tradicional busca inserir elementos históricos, uma representação mais aberta da homossexualidade que, na época de Sirk, não teria tido espaço, uma vez que a vigência do Código Hayes proibia qualquer manifestação de ordem sexual: cenas de beijos ardentes, sexo, nudez eram proibidas ou qualquer incitação era "barrada" por um comitê composto por uma direita conservadora que ganha seu apogeu durante a época McCartista. O Código Hayes perdurou de 1930 a 1968, quando foi criado um órgão de censura prévia a filmes lançados por Hollywood. Além de temas relacionados à sexualidade, mesmo heteronormativa, o código também "patrulhava" qualquer subtema relacionado a valores esquerdistas (a valorização do socialismo, por exemplo), realizando cortes nos filmes ou banindo roteiristas, diretores e atores que adotassem qualquer postura contra os "valores americanos", família e propriedade.

No filme de Todd Haynes, além da representação da homossexualidade num contexto que nunca pôde ser mostrado nos filmes de Sirk, a questão racial torna-se um tema subjacente ao tema central da submissão feminina, uma mulher que vive um casamento perfeito até flagrar o marido com outro homem no seu escritório. Cathy Whitaker é o estereótipo da mulher americana dos anos cinqüenta: dona de casa disciplinada que luta para manter a unidade familiar, mesmo quando descobre a homossexualidade latente do marido, Frank. Nesse ínterim, aproxima-se do jardineiro 
negro, Raymond Deagan, por quem desenvolve laços afetivos à medida que percebe o distanciamento do marido e da sociedade local que a rejeita.

A palavra melodrama é de origem francesa, mas sua formação vem do grego melo (música) e drama (ação), portanto, o uso constante da música contribui para o engendramento da ação que caminha para um desfecho construído a partir de um leitmotiv ou tema. Segundo Patrice Pavis, o melodrama tem sua origem no século XVIII a partir de uma espécie de opereta popular "no qual a música intervém nos momentos mais dramáticos para exprimir a emoção de uma personagem silenciosa" (PAVIS, 1999, p. 238). O uso contínuo da música é utilizado para marcar a construção de um determinado conflito individual que se estabelece entre o que entendemos por persona (personagem) e o que a conduz (leitmotiv).

Em Longe do Paraíso, a música é conduzida e orquestrada por Elmer Bernstein, famoso compositor de trilhas sonoras, cuja característica principal é trabalhar com temas suspensos como ocorre em filmes como Cabo do Medo ${ }^{5}$ A primeira música do filme é Autumn in Connecticut, que estabelece a estrutura narrativa na qual o filme é desenvolvido, o drama de estações, bebendo na fonte teatral de August Strindberg. O tema da personagem principal, Cathy, é o Mother Love, que se desdobra em outros temas que descrevem o cotidiano/microcosmo da vida na cidade de Hartford, tendo como espaço os suburbs habitados por uma classe média branca e ascendente economicamente no pós-guerra em 1958. As composições de Bernstein alternam entre o pueril (ambiente doméstico e cenas exteriores, paisagem outonal de Hartford) e dramáticas (descobertas, crises na família, dentre outros).

A formalidade impera nos gestos e costumes que Haynes procura reproduzir nos diálogos, figurinos e direção de arte, assim como podemos ver nos filmes de Douglas Sirk. O registro de preciosismos nos diálogos estabelece a formalidade constante ao estabelecer os papéis sociais que cada personagem ocupa na narrativa: a esposa dedicada, o marido trabalhador, os filhos (um casal de crianças), a empregada negra leal e prestativa, as vizinhas e amigas contempladoras da aparente felicidade do casal protagonista.

\footnotetext{
${ }^{5}$ Cape Fear (1991), filme dirigido por Martin Scorcese.
} 
Estamos na era Eisenhower ${ }^{6}$, político popular, que conduz uma América em todo seu auge na construção do American Dream. De fato, Cathy e Frank Whitaker representam o casal modelo do capitalismo, Mr. e Mrs. Magnetch, quando são entrevistados para uma revista especializada em descrever o cotidiano do bairro em que moram. Apontados como casal modelo de sucesso, eles representam o modelo heteronormativo de uma sociedade branca de classe média: as meninas devem se identificar com o modelo feminino de austeridade e supressão dos desejos e ambições para viver uma existência marcada pela contemplação e submissão aos caprichos do macho branco, enquanto os meninos devem ter o pai como referencial na sua constante busca por atenção e competitividade, mimados e elevados à condição de superioridade. A cena da mesa descreve o modelo de ambiente familiar saudável a ser copiado e reproduzido: o filho e sua partida de futebol na escola, enquanto a filha fala da apresentação de balé; cabe ao pai assistir à partida do filho na escola, enquanto a mãe acompanha a menina na sua apresentação. O aspecto ritualístico desses afazeres domésticos não pode ser quebrado para que a unidade familiar não seja colocada em xeque: a comodidade e a repressão parecem andar de mãos dadas com a conveniência das relações que as produzem.

A quebra desse modelo ocorre quando o marido é apanhado pela polícia num ambiente de cruising ${ }^{7}$ (entendido aqui como "pegação" ambiente no qual os homossexuais procuram sexo anônimo). O diretor opta por manter o suspense até que a conclusão ocorre numa das cenas cruciais e melodramáticas do filme, quando, por um acaso, a mulher vai visitar o marido no escritório.

Há elementos simbólicos no filme, como a passagem do tempo (outono para inverno) que significa a morte do sonho ou a destruição do paraíso, justificando o

${ }^{6}$ D. Dwight Eisenhower (1890-1969), presidente norte-americano durante 1953-1961, responsável por uma política conservadora com o intuito de estabelecer os Estados Unidos como potencial mundial e de grande influência na política internacional, estabelecendo uma política de interesses comerciais para atenuar a tensão entre os EUA e a antiga URSS.

${ }^{7}$ Um dos assistentes de polícia chama Frank de loiterer que em inglês significa alguém que vaga por lugares de forma suspeita (Dicionário Oxford, 1995). 
título do filme. O drama de estações ${ }^{8}$ é comum na literatura dramática, já que podemos ver o mesmo nas peças de Tennessee Williams (Um Bonde Chamado Desejo e Summer and Smoke), pois a idéia da continuidade, a passagem das estações e a narrativa fragmentada em cenas episódicas estabelecem uma ação que se desenvolve; o outono enquanto símbolo da morte lenta, o inverno constatação e luto, e a primavera, renascimento. Aqui também podemos dizer que o drama de estações está também calcado na individualidade do herói em seqüências episódicas, como se dava na formulação aristotélica.

Outro elemento de pontuação dramática é a bebida,que aparece como ameaça à unidade familiar; o que acaba por remeter a uma tradição na literatura dramática norte-americana, quando os dramas familiares envolvem o alcoolismo como subtema e símbolo da sua desintegração: Quem tem medo de Virgínia Woolf?, de Edward Albee, Longa Jornada Noite Adentro, de Eugene O'Neill, dentre outros. A bebida entendida aqui como escape para as angústias das personagens, eterno fantasma na história norteamericana se considerarmos os tempos da Grande Depressão e a Lei Seca, retratados em romances como $O$ Grande Gatsby, de F. Scott Fitzgerald, por exemplo.

A Lei Seca (as Prohibition Laws), implementada como emenda institucional em 1920-1933, foi o pretexto para se realizar na prática a perseguição a anarquistas e comunistas impunemente em território norte-americano. O argumento é de que a bebida produzia a desintegração das famílias, apoiando-se na afirmação complementar de que a bebida era particularmente devastadora nas classes mais baixas. Essa questão da bebida é freqüente na história norte-americana, embora, na fachada, a ideologia fosse a da moral puritana e quaker (Benjamin Franklin era ardoroso defensor da idéia da temperança em seus artigos) e a da preservação da família e da ordem, sendo mais tarde utilizado pelo Estado para controlar qualquer manifestação política no país.

\footnotetext{
${ }^{8}$ Ver Teoria do Drama, de Peter Szondi, que analisa peças de August Strindberg, "pai" do drama de estações: SZONDI, P. Teoria do Drama Moderno. Tradução de Sérgio Rêpa. São Paulo: Cosac \& Naify, 2002.
} 
Todd Haynes desenvolve uma espécie de construção em abismo, o mys-enbyme, termo de André Gide ${ }^{9}$, quando desenvolve uma espécie de intertextualidade entre o drama de Frank (homossexual, casado e sua vida dupla), quando este vai ao cinema assistir ao filme As Três Faces de Eva (1957), melodrama popular sobre uma mulher que tem tripla personalidade.

Haynes também trabalha com o deslocamento de espaço quando propõe a oposição entre o claro e o escuro. $\mathrm{O}$ claro representa aquilo que é considerado aceitável para a sociedade (a imagem da família feliz e integrada) e o escuro (lugar dos marginalizados, homossexuais e negros). Há também a organização geográfica de Hartford que se divide entre o downtown (centro comercial) e o suburbs (os bairros residenciais) para descrever o quanto a noção de espaço era preciosa para os americanos na época.

A distinção entre o coletivo e o privado é essencial: o lugar dos negócios, o escritório de Frank Whitaker, espaço por excelência do homem de classe média, enquanto a casa é o espaço do feminino. Assim como os papéis das personagens e sua função dentro do patriarcado protestante e capitalista, o espaço acaba por estabelecer os conflitos das personagens à medida que a oscilação e a interferência de elementos estranhos entre os espaços podem ser prejudiciais para a harmonia e manutenção dos mesmos.

Por outro lado, há outros espaços que escapam da imagem do Paraíso Perdido de Hartford. Um deles é o clube noturno gay que Frank freqüenta, representando o espaço dos marginalizados na sociedade, assim como o clube dos negros para onde Cathy e Raymond se dirigem.

Com efeito, Raymond afirma que há outros mundos que Cathy, a dona de casa alienada, desconhece, como o bairro periférico, onde os negros de Hartford vivem ignorados pela sociedade branca local, a não ser nos serviços que estes podem prestar aos mesmos, serviços de jardinagem, consertar carros, limpar uma casa, dentre outros.

\footnotetext{
${ }^{9}$ Para Jacques Aumont e Michel Marie, mise en abîme (construção em abismo), é um termo que descreve a incrustação "de uma narrativa em outra, por analogia com o termo brasão que designa uma figura colocada no centro do escudo, e que figura outro escudo" (AUMONT; MARIE, 2003, p. 60). Podemos acrescentar a imagem do espelho que, a partir de um outro espelho, reflete inúmeras imagens, técnica comum no cinema referencial de cineastas como Brian de Palma e Pedro Almodóvar.
} 
A postura de Cathy é ser politicamente correta quanto à sua ignorância de um mundo exterior que não consegue enxergar, ao apoiar a N.A.A.C.P $\mathrm{P}^{10}$; ela recusa-se a ser rotulada como preconceituosa ao demonstrar um certo estranhamento com a visita de Raymond a uma galeria de arte, quando ela não compreende sua presença no evento social, uma vez que negros não teriam acesso à cultura e noção de arte moderna. A presença de negros na galeria mostra a divisão de mundos entre brancos e negros; e Raymond busca acreditar que pode fazer parte: sua filha é vista como a esperança, pois ele deseja que ela faça parte desse mundo como um sonho a ser concretizado e remete ao discurso de Martin Luther King sobre a integração racial entre negros e brancos.

$\mathrm{Na}$ galeria, a arte moderna de Picasso e Miró representa o moderno em contraposição ao antiquado e tradicional: a classe média vê a arte com curiosidade, embora não a compreenda na sua tentativa de renovar. Para essa mesma classe média, a exposição de arte moderna é apenas mais um evento social numa cidade provinciana como a de Hartford, Connecticut, no norte dos Estados Unidos.

É interessante o uso do lenço como elemento dramático, quando o vento carrega o lenço púrpura de Cathy, encontrando-o no quintal de sua casa, onde Raymond trabalha como seu jardineiro; temos aqui a união desses dois mundos, o do negro com diploma superior, mas reduzido à condição de jardineiro no mundo dos Whitakers e a da mulher infeliz no casamento, representada por Cathy que se desdobra para manter a unidade familiar até às últimas consequiências quando se vê abandonada pelo marido e amigos.

A representação da opressão à mulher pode ser vista no grupo de discussão, quando Cathy reúne algumas amigas para discutir sobre sexo: a questão sexual é tida como um tabu a ser discutido por mulheres de classe média quando comentam a quantidade de vezes que fazem sexo. É curioso observar o embaraço que a situação provoca entre as personagens, uma vez que a quantidade de vezes que os casais fazem sexo - quanto maior a quantidade, mais as mulheres se sentem indignadas - descrevem

${ }^{10}$ The National Association for the Advancement of Colored People (NAACP), associação popular que luta pelos direitos civis dos negros, fundada em 1909, desenvolvendo um trabalho de integração racial até o presente momento. 
o quanto aquelas pacatas donas de casa se sentem incapazes de lidar com seu próprio desejo.

Aliás, a domesticação do desejo é constante, quando o tema da homossexualidade (ou homossexualismo se considerarmos que esse era o termo utilizado na época) é descrito como doença, passível de cura. Frank procura um especialista que descreve vários tipos de tratamentos na época: eletrochoque, heterosexual conversion, influenciadas por métodos behaviouristas, assim como o uso de hormônios reguladores.

O diálogo entre médico e o paciente descreve os métodos utilizados na época para um tratamento para a homossexualidade:

Doctor Bowman: Today the general attitude regarding this sort of behavior is naturally more modern, more scientific than it ever before. But for those do seek treatment, who possess the will and desire to lead a normal life, there still remains only a scant five to thirty percent rate of success... For complete heterosexual conversion.

Frank: I can't let this "thing” destroy my life, my family's life I know it's a sickness because it makes me feel despicable. I promise you Doctor Bowman, I'm going to beat this thing. I'm gonna break it.

A teatralidade do bem e do mal é a base do melodrama enquanto representação de valores de uma espécie de moral coletiva. De fato, Virtude e Dignidade são características essenciais para os protagonistas do melodrama, mesmo que esses traços pareçam distorcidos para o espectador atual diante da fragilidade das instituições em que a moral se constrói: a família, Igreja, Governo, dentre outros. Como bem observa Ismail XAVIER, "a virtude de caráter de um personagem sanciona a sua posição política, a hipocrisia o esvazia" ${ }^{11}$ (2004, p. 95). O herói não pode escapar da virtude, assim como o vilão/antagonista por excelência não pode demonstrar ambigüidades, já que não é possível relativizar a bondade e a maldade.

O caráter sentimental do melodrama pode ser visto como uma forma de estabelecer uma verdade comum e coletiva, cujo intuito é enfrentar as ameaças e os desenganos de uma sociedade repressora do indivíduo comum. A identificação de quem assiste/presencia o "conflito alheio" faz com que o espectador atue como uma

${ }^{11}$ XAVIER, I. O olhar e a cena. São Paulo: Cosac \& Naify, 2004. 
espécie de testemunha para reduzir as ambigüidades, simplificando-as na maioria das vezes como podemos ver nas telenovelas, derivadas do Drama burguês ${ }^{12}$. Com efeito, Peter Brooks, citado por Ismail XAVIER (2004, p. 89) descreve a hegemonia do melodrama como uma combinação de sentimentalismo e prazer visual (figurinos e cenários rompantes), como elemento ligado à indústria cultural.

O espectador do melodrama é auto-indulgente e permite que as imagens celebrem uma espécie de imposição de valores morais, evocando sentimentos nobres que esse consumidor em potencial julga ter perdido diante de uma "realidade" (que ele próprio desconhece qual seja) massacrante, despida de sonho e fantasia. O cinema é receptáculo desse universo que chama a atenção do espectador para a forma, seduzindo a partir da embalagem, tornando o espectador/consumidor sujeito ignorante do próprio conteúdo (crítico ou não) da realidade que ele tanto deseja desprezar e questionar, quando adere ao processo de identificação (herói/mocinha). É curioso observar, no entanto, o quanto o espectador contemporâneo parece desprezar essa própria dualidade do melodrama, quando o antagonista (vilão/vilã) consegue chamar mais atenção do que o protagonista (mocinho/mocinha).

Longe do Paraíso pode ser visto como uma tentativa de romper com as estruturas do melodrama, à medida que, diferentemente da narrativa tradicional, não temos aqui a teatralidade do mal personificada, ou seja, um vilão ou antagonista, mais a condensação do mal no coletivo que rejeita os protagonistas do filme: a mulher liberal, o negro e o homossexual. É interessante observar que esses dois pólos, bem e mal, acabam por revelar o quanto o melodrama poderia ser uma forma de condensar e explorar essa moralidade (no caso, a valorização da unidade familiar a todo custo), quando esta parece deslocada e perdida, tentativa de uma idealização romântica do pequeno burguês, a felicidade no casamento.

A nostalgia dos anos 50 tão explorada por Hollywood aqui se desloca para um epicentro de referências que não nos permite enxergar apenas o drama doméstico e a elegância da classe média norte-americana, mas sua desintegração e distanciamento

\footnotetext{
${ }^{12}$ Ver SZONDI, P. Teoria do drama burguês. Tradução de Luiz Sérgio Repa. São Paulo: Cosac \& Naify, 2004.
} 
como o próprio título do filme sugere, Longe do Paraíso (ou do Sonho Americano). Há referências históricas que estabelecem fatos que ocorrem ao longo da narrativa como o incidente em Topeka, quando uma garota chamada Linda Brown torna-se a primeira negra a participar de uma política de integração racial nas escolas norteamericanas a partir de uma batalha judicial que mobilizou o estado e a mídia norteamericana, fato comentado por uma das personagens de Longe do Paraíso.

Fredric Jameson chama atenção para uma manifestação cultural sobre o filme de nostalgia que reproduz "uma nova conotação de 'anterioridade' e de profundidade pseudo-histórica, na qual a história dos estilos estéticos desloca a história "real"" (JAMESON, 2000, p. 47). Essa valorização da estética da nostalgia ressalta a valorização do passado enquanto fonte de inspiração para artistas que apenas reproduzem a ideologia de que a história é um elemento secundário, pois a contextualização da obra da arte no tempo é mero subterfúgio para copiar um estilo que se resume ao pastiche.

No caso de Longe do Paraíso, Todd Haynes procura fugir da representação nostálgica dos anos 60, inserindo o tema da homossexualidade e interligando-o a outros como a emancipação feminina e o racismo. Em outros filmes do diretor, como Velvet Goldmine ${ }^{13}$, por exemplo, há o cuidado de historicizar a partir do microcosmo para atingir o macrocosmo. Nesse filme, em particular, temos a descrição dos anos 60 e a efervescência cultural daquele período inspirado na relação de dois ícones da contra-cultura (David Bowie e Iggy Pop), abordando temas como a bissexualidade e as drogas, narrado pela esposa do protagonista num processo de distanciamento após o fim do casamento, espécie de reflexão sobre o período, suas influências e impacto cultural. Esse aspecto libertário dos anos 60 é explicitado em Eros e Civilização ${ }^{14}$ de Herbert MARCUSE, quando o autor analisa o impacto da libertação sexual no período, sendo o próprio livro fruto dessa época.

Como Douglas Sirk percebia a dificuldade de tratar o tema da homossexualidade nos anos 50, proibido pelo Código Hayes, consegue relacionar

${ }^{13}$ Velvet Goldmine (1998), dirigido por Todd Haynes, disponível em VHS até o momento.

${ }^{14}$ MARCUSE, H. Eros e civilização. Tradução de Álvares Cabral. Rio de Janeiro: LTC, 1999. 
Longe do Paraíso à Era Bush, à medida que o filme tem como embate valores de uma América corrompida em detrimento do discurso favorável à unidade familiar tão presente na plataforma ideológica do Partido Republicano.

Em Bastidores de Hollywood, William J. Mann descreve a influência de gays e lésbicas no cinema durante os anos de 1910-1969. A expressão "bastidores" é emblemática, pois sugere o uso de uma estética gay do glamour na construção dos mitos hollywoodinos: a persona enigmática de Greta Garbo, a ambigüidade de Marlene Dietrich e o humor camp de Mae West que hoje são abertamente admiradas como ícones gays. Em seu livro, William J. Mann observa que havia uma tolerância quanto aos homossexuais na indústria hollywoodiana, desde que eles não passassem para frente das câmeras. Na sua maioria eram profissionais técnicos (figurinistas, compositores, roteiristas) que ajudaram a construir esses ícones de uma Hollywood mítica, valorizando a elegância e reforçando o brilho fabricado do star system.

Entretanto, o que mais se observa é a existência de gays com poder de decisão na indústria cinematográfica se considerarmos diretores como George Cukor, Billy Wilder, além de astros como Gary Cooper, Rock Hudson e Burt Lancaster, mas que dificilmente teriam liberdade para discutir a homossexualidade nas telas, dominados pelo star system hollywoodiano que perdura até os nossos dias.

Longe do Paraíso parece fazer parte de uma leva de filmes que procura revisitar fatos históricos que dialogam com o presente momento, quando o conservadorismo republicano está em alta em choque com uma Hollywood progressista (ou oportunista?) que rejeita a política Bush. De fato, o filme integra-se a uma espécie de estrutura de sentimento (termo de Raymond Williams) que, ironicamente, acaba por revelar brechas na indústria cinematográfica na discussão de temas e projetos como esse de Haynes, oriundo do Festival de Sundance; projeto criado por um ícone hollywoodiano, Robert Redford, apostando em diretores e roteiristas jovens, fora do circuito comercial. Há de se prever a cooptação por parte desses artistas pela indústria cultural norte-americana; porém, é curioso como essa movimentação acaba por revelar trabalhos que recriam e dão novo significado a 
fórmulas (aparentemente) gastas como o melodrama, sob uma perspectiva criativa e histórica.

\section{Referências bibliográficas}

AUMONT, J.; MARIE, M. Dicionário Teórico e Crítico de Cinema. Tradução de Eloísa Araújo Ribeiro. São Paulo: Papirus, 2003.

BROOKS, P. The melodramatic imagination: Balzac, Henry James, melodrama and the mode of excess with a new preface. New Haven: Yale University Press, 1995.

HUPPES, I. Melodrama: o gênero e sua permanência. Cotia-SP: Ateliê Editorial, 2000 .

JAMESON, F. As marcas do visível. Rio de Janeiro: Graal, 1995.

MARCUSE, H. Eros e civilização. Tradução de Álvares Cabral. Rio de Janeiro: LTC, 1999.

PAVIS, P. Dicionário de Teatro. Tradução de J. Guinsburg e Maria Lúcia Pereira. São Paulo: Perspectiva, 1999.

SZONDI, Peter. Teoria do drama moderno. Tradução de Luiz Sérgio Rêpa. São Paulo: Cosac \& Naify, 2003.

. Teoria do drama burguês. Tradução de Luiz Sérgio Repa. São Paulo: Cosac \& Naify, 2004.

XAVIER, I. O olhar e a cena. São Paulo: Cosac \& Naify, 2004. 